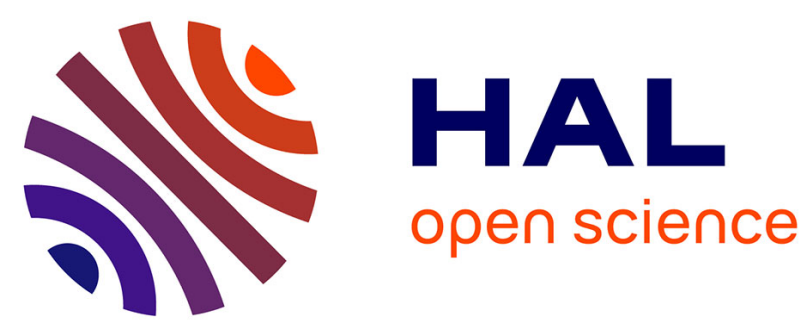

\title{
Mesenchymal and neural stem cells labeled with HEDP-coated SPIO nanoparticles: in vitro characterization and migration potential in rat brain.
}

Gaëtan J.-R. Delcroix, Matthieu Jacquart, Laurent Lemaire, Laurence Sindji, Florence Franconi, Jean-Jacques Le Jeune, Claudia N. Montero-Menei

\section{To cite this version:}

Gaëtan J.-R. Delcroix, Matthieu Jacquart, Laurent Lemaire, Laurence Sindji, Florence Franconi, et al.. Mesenchymal and neural stem cells labeled with HEDP-coated SPIO nanoparticles: in vitro characterization and migration potential in rat brain.. Brain Research, 2009, 1255, pp.18-31. 10.1016/j.brainres.2008.12.013 . inserm-00354437

\section{HAL Id: inserm-00354437 https://www.hal.inserm.fr/inserm-00354437}

Submitted on 19 Jan 2009

HAL is a multi-disciplinary open access archive for the deposit and dissemination of scientific research documents, whether they are published or not. The documents may come from teaching and research institutions in France or abroad, or from public or private research centers.
L'archive ouverte pluridisciplinaire HAL, est destinée au dépôt et à la diffusion de documents scientifiques de niveau recherche, publiés ou non, émanant des établissements d'enseignement et de recherche français ou étrangers, des laboratoires publics ou privés. 


\section{Mesenchymal and neural stem cells labeled with HEDP-coated SPIO nanoparticles:}

\section{in vitro characterization $\&$ migration potential in rat brain}

Gaëtan J-R DELCROIX ${ }^{1,2}$, Matthieu JACQUART ${ }^{1,2}$, Laurent LEMAIRE ${ }^{1,2}$, Laurence SINDJI ${ }^{1,2}$,

Florence FRANCONI ${ }^{3}$, Jean-Jacques LE JEUNE ${ }^{1,2}$, Claudia N. MONTERO-MENEI ${ }^{1,2}$

${ }^{1}$ Inserm, U646, Angers, F49100 France

${ }^{2}$ Univ Angers, UMR-S646, Angers, F49100 France

${ }^{3}$ SCAS, Univ Angers, Angers, F49045 France

Total number of pages: 36 (including 6 figures and 3 tables)

Grant information: this work was supported by the "Région Pays de la Loire" and "INSERM"

Corresponding author: Claudia N. Montero-Menei

Inserm U646, 10 rue André Boquel, Angers, France

Phone : $+33(0) 2.41 .73 .58 .94$

Fax : $+33(0) 2.41 .73 .58 .53$

E-mail : claudia.montero-menei@ univ-angers.fr 


\begin{abstract}
Mesenchymal stem cells (MSC) may transdifferentiate into neural cells in vitro under the influence of matrix molecules and growth factors present in neurogenic niches. However, further experiments on the behavior of such stem cells remain to be done in vivo. In this study, rat MSC (rMSC) have been grafted in a neurogenic environment of the rat brain, the subventricular zone (SVZ), in order to detect and follow their migration using superparamagnetic iron oxide (SPIO) nanoparticles. We sought to characterize the potential effect of iron loading on the behavior of rMSC as well as to address the potential of rMSC to migrate when exposed to the adequate brain microenvironment. 1hydroxyethylidene-1.1-bisphosphonic acid (HEDP)-coated SPIO nanoparticles efficiently labeled rMSC without significant adverse effects on cell viability and on the in vitro differentiation potential. In opposition to iron-labeled rat neural stem cells (rNSC), used as a positive control, iron-labeled rMSC did not respond to the SVZ microenvironment in vivo and did not migrate, unless a mechanical lesion of the olfactory bulb was performed. This confirmed the known potential of iron-labeled rMSC to migrate toward lesions and, as far as we know, this is the first study describing such a long distance migration from the SVZ toward the olfactory bulb through the rostral migratory stream (RMS).
\end{abstract}

Section: cellular and molecular biology of nervous system

Keywords: mesenchymal stem cells; SPIO; cell migration; subventricular zone; olfactory bulb; magnetic resonance imaging

Abbreviation list: BrdU: bromodeoxyuridine; BSA: bovine serum albumin; DMEM: Dulbecco's modified Eagle's medium; DPBS: Dulbecco's phosphate buffered saline; EDX: energy dispersive X-ray; FBS: foetal bovine serum; HEDP: 1-hydroxyethylidene-1.1-bisphosphonic acid; HG: high glucose; IHC: immunohistochemistry; LG: low glucose; MIAMI: marrow isolated adult multilineage inducible; MRI: 
magnetic resonance imaging; MSC: mesenchymal stem cell; OB: olfactory bulb; PB: Prussian blue; PFA: paraformaldehyde; RMS: rostral migratory stream; rMSC: rat mesenchymal stem cell; rNSC: rat neural stem cell; RT: room temperature; SEM: scanning electron microscopy; SPIO: superparamagnetic iron oxide; SVZ: subventricular zone; TEM: transmission electron microscopy 


\section{INTRODUCTION}

Stem cells are often described as the best candidates for cell therapy studies due to their selfrenewal capacity and their large differentiation potential. Among them, mesenchymal stem cells (MSC) remain easy to isolate and expand. They may exhibit immunodepressive characteristics which make them less sensitive to rejection by the host immune system [25,30,34]. Moreover, MSC allow autologous grafts to be performed in cell therapy protocols. Bone marrow MSC typically differentiate into connective tissue cell types [12,21], but various laboratories have also reported the transdifferentiation potential of MSC into a neuronal-like phenotype $[5,39,46]$. We previously showed that a subpopulation of human MSC, marrow-isolated adult multilineage inducible (MIAMI) cells may trandifferentiate in vitro in a neurotrophin-dependent manner into neuronal-like cells. These cells express neuronal markers and present electrophysiological characteristics similar to those observed in mature neurons [44]. Moreover, a fraction of MSC transplanted in adult rat brains may respond to microenvironmental cues and transdifferentiate into neuronal-like cells [20,23,52]. Using different brain lesion models, it has been shown that implanted MSC may be involved in functional improvement, either directly or indirectly by their ability to produce various growth factors $[9,27,28,51]$. In addition, a damaged environment resulting e.g. from ischemia or from the presence of a tumor is known to stimulate the migration of transplanted MSC [20,28,41] as well as of neuronal precursors $[1,22]$. MSC may thus be considered as potential candidates for cell therapy studies in the central nervous system. However, the possible use of MSC for brain repair studies still requires an evaluation of their behavior, migratory dynamic and fate in vivo. Moreover, as only a fraction of the transplanted cells may respond to the stimuli of the microenvironment, highly sensitive procedures will be required in the future.

Magnetic resonance imaging (MRI) is a non-invasive tool that has demonstrated a high sensitivity for cell tracking after systemic or in situ injection of cells having incorporated magnetic tags. Indeed, using phagocytic cells, the detection of a single cell in mouse brain has been obtained with this technique [19]. This strategy spares laboratory animals and ultimately may be used for human stem cell 
therapy studies. Toward this end, new magnetic tracers readily and specifically taken up by stem cells need to be formulated. Superparamagnetic iron oxide (SPIO) nanoparticles stand as promising tools to label and track various cell types in vivo by MRI $[6,31,43]$. We developed SPIO nanoparticles coated with 1-hydroxyethylidene-1.1-bisphosphonic acid (HEDP) [38], which are interesting due to their possible functionalization allowing the targeting and uptake of a specific cell type. In order to be able to translate this tool into the clinic, the innocuousness and the non-interference of these nanoparticles with the response of stem cells to their microenvironment have to be demonstrated.

In this study, we sought to characterize the potential effects of labeling rat MSC (rMSC) with these HEDP-coated SPIO nanoparticles on their viability and functions in vitro. Toward this end, rMSC iron uptake was characterized in vitro by Prussian blue (PB) staining and MRI. Iron-labeled rMSC viability and ultrastructure were also studied, as well as their osteogenic and neuronal differentiation potentials. Furthermore, we assessed the migratory potential of these iron-labeled MSC in vivo in response to the brain neurogenic stimuli. Indeed, it has been shown that neural stem cells (NSC) migrated from the subventricular zone (SVZ) to the olfactory bulb $(\mathrm{OB})$, via the rostral migratory stream (RMS), where they differentiate into post-mitotic interneurons [11]. Therefore, we studied the ability of iron-labeled rMSC to migrate in a similar fashion than iron-labeled rat neural stem cells (rNSC), when transplanted into the SVZ of the lesioned or non-lesioned rat brain. This study was performed by bromodeoxyuridine (BrdU) immunohistochemistry (IHC) and PB staining. Finally, a double staining with $\mathrm{PB} / \mathrm{CD} 11 \mathrm{~b}$, specific for macrophage/microglia, was used to confirm the fate of the grafted cells and of the SPIO nanoparticles. 


\section{RESULTS}

\section{Iron uptake and cell characterization}

Prussian blue staining, after incubation of the rMSC with the iron-oxide nanoparticles, demonstrated that the intensity and the percentage of labeled cells increased with the iron concentration used. Forty eight hours incubation with an amount of nanoparticles corresponding to $25 \mu \mathrm{g}$ iron $/ \mathrm{mL}$ resulted in ca. $10 \%$ of Prussian blue positive cells, $50 \mu \mathrm{g} / \mathrm{mL}$ efficiently labeled more than $90 \%$ of the cells whereas $100 \mu \mathrm{g}$ iron/mL did not increase the percentage of positive cells compared to $50 \mu \mathrm{g}$ iron/mL (fig. 1A, B, C respectively). For rNSC, PB staining revealed that 24 hours of incubation with 50 $\mu \mathrm{g} / \mathrm{mL}$ iron gave the most efficient labeling (fig. 1D). rNSC were expanded as floating clusters called neurospheres but incubation in the iron containing medium was performed on adherent progenitors as the 3D structure of the neurospheres prevented an efficient labeling of all the cells.

Spectroscopic iron titration confirmed that the iron content per rMSC varied with the nanoparticle concentration used during labeling. Over the concentration range used (from 25 to $100 \mu \mathrm{g}$ iron $/ \mathrm{mL}$ ), the intracellular concentration increased from ca. $3.5 \mathrm{pg} / \mathrm{cell}$ to $10 \mathrm{pg} / \mathrm{cell}$ (table 1$)$. The differences in iron content per cell were also observed using in vitro MRI. Indeed, fig. 1E shows typical $\mathrm{T} 2 *$-weighted images of an agarose gel containing iron-labeled rMSC. As the iron concentration increased in the incubation media, the $\mathrm{T} 2 *$ effects induced by the cells increased. Thus, cells incubated with $50 \mu \mathrm{g}$ iron/mL induced a global T2* reduction of ca. 50\% compared to unlabeled cells.

Trypan blue counting and MTS assay showed that cell viability was not affected one day postincubation when using 25 or $50 \mu \mathrm{g}$ iron $/ \mathrm{mL}$, whereas it decreased to $70 \%$ of control with $100 \mu \mathrm{g}$ iron/mL. Consequently, $50 \mu \mathrm{g}$ iron/mL incubated for 48 hours was chosen as the best trade-off in terms of iron content, percentage of marked cells and cell viability. It resulted in an average concentration of $5.6 \pm 1.6 \mathrm{pg}$ iron/cell as determined by spectroscopic iron titration (table 1). It should be noted that the facilitating Fugene ${ }^{\circledR}$ reagent was tested but did not significantly enhance iron uptake (data not shown). It was consequently not used in this study. 
Under these conditions, iron-labeled cells did not exhibit morphological differences with unlabeled cells (fig. 2A, B). Moreover, transmission electron microscopy (TEM) demonstrated that ironlabeling did not affect rMSC ultrastructure and that the SPIO nanoparticles were taken into the cells rather than adhering to the exterior of the membrane. They were located in endo-lysosomial vesicles with a mean diameter of $355 \mathrm{~nm}$ (fig. 2C). Observations by scanning electron microscopy (SEM) confirmed the intracytoplasmic and perinuclear distribution of the nanoparticles. The small white dots observed on back-scattered SEM images (fig. 2D) were correlated to a difference in molecular composition and an energy dispersive x-ray (EDX) spectrum confirmed their iron nature (fig. 2E).

To confirm that iron-labeled rMSC maintain their function in vitro, differentiation studies were performed. Iron-labeled rMSC were still able to undergo an osteogenic differentiation. Moreover, a similar proportion of cells responded to this induction when compared to the control, unlabeled cells, as shown by Alizarin red staining of hydroxyapatite associated calcium mineral deposits (fig. 3A, B). In addition, rMSC developed features of neuronal cells in response to published protocols [49]. Most importantly, there was no significant difference between unlabeled and iron-labeled rMSC responses to the neuronal induction in vitro. Flat, uninduced rMSC expressed low levels of nestin and $\beta 3$-tubulin (table 2). When exposed to the neuronal induction medium, some cells detached but most of them exhibited a narrower morphology that evolved towards a neuronal-like morphology, ranging from simple bipolar to branched cells (fig. 3C to H). Moreover, rMSC with a neuronal-like morphology acquired the expression of the neural-related markers nestin and $\beta 3$-tubulin. Up to $50 \%$ and $65 \%$ of rMSC were positive for nestin and $\beta 3$-tubulin, respectively, 24 hours post-induction. $\beta 3$-tubulin expression remained stable 48 hours post-induction whereas nestin expression decreased to 5-35\% positive cells (table 2). The neuronal marker NeuN was already expressed in expanding cells and at a similar level at every step of the neuronal induction (fig. 3G, H).

\section{Labeling for histochemical detection}


Different in vitro labeling techniques (Hoechst 33342, PKH26, GFP transduction and BrdU) were tested to co-localize the iron-labeled cells after transplantation and determine their fate in vivo. PB staining of the labeled cells in vitro demonstrated that none of the methods used significantly interfered with iron uptake. However, some of these techniques were not completely satisfactory. Co-culture experiments with GFP-positive rMSC and Hoechst 33342-positive rMSC demonstrated that Hoechst fluorescent dye diffused into GFP-positive rMSC. PKH26 was readily absorbed by the rMSC and did not diffuse to the surrounding cells but the correct visualization of the cells was impaired in vivo due to a weak fluorescent signal. Lentiviral transduction yield of GFP was around $80 \%$ but resulted in a decreased cell proliferation rate, as well as a lower response of the cells to neuronal induction in vitro (data not shown).

Cell detection by PB staining and BrdU IHC was the most suitable labeling strategy, in our hands, to study the in vivo distribution of iron-labeled rMSC in rat brains. A minimum incubation time of 72 hours was used to label $90 \%$ of the iron-labeled rMSC in vitro with BrdU (fig. 4A). Indeed, an incubation time of 48 hours resulted in only $40 \%$ of BrdU positive rMSC (fig. 4B). The rapidly dividing iron-labeled rNSC were efficiently labeled with BrdU after only 6 hours incubation (fig. 4C). These incubation times were then used to load the cells with BrdU prior to transplantation.

\section{In vivo detection of rNSC and rMSC}

In the non-lesioned brain model, rMSC grafted into the SVZ did not respond to the stimuli of the neurogenic microenvironment and were only found in the grafting site (fig. 5A). Preliminary results indicated that, 5 days after grafting, rMSC close to the injection site stained positive for nestin as well as slightly for $\beta 3$-tubulin (data not shown). We demonstrated that a mechanical lesion of the OB strongly induced the migration of rMSC to the OB through the RMS. This migratory behavior was confirmed by the visualization of the cells on adjacent brain slices both by BrdU IHC and PB staining 4, 14 and 21 days after transplantation, with a fainter staining after 21 days. The pathway followed by the cells from 
the injection site to the OB was approximately $7 \mathrm{~mm}$ long. Time after grafting was a critical parameter as only a few migrating cells were observed 4 days after transplantation whereas the highest number was observed after 14 days. A fraction of cells were observed near the injection tract, but also all along the RMS and many of them reached the $\mathrm{OB}$ and were dispersed in this region (fig. $5 \&$ table 3 ). Prussian blue staining performed on control rats was negative; therefore confirming that PB staining in the grafting site as well as in the lesioned $\mathrm{OB}$ was specific for iron-labeled cells and did not result from endogenous iron deposit. No strong inflammatory reaction was observed with CD11b staining, a specific marker for macrophage/microglia. Moreover, $\mathrm{PB} / \mathrm{CD} 11 \mathrm{~b}$ double staining revealed a co-localization of this marker with only a few PB-positive cells, but not with the entire PB-positive cell population (fig. $5 \mathrm{~K}, \mathrm{~L})$.

However, even though PB staining revealed a large number of iron-labeled rMSC in the lesioned OB region after the mechanical lesion (fig. 5D), this pool of migrating cells was not accessible to MRI as the lesion itself was responsible for a large hyposignal and labeled cells were only efficiently visualized at the grafting site (fig. 6A, B).

In non-lesioned rat brains, rNSC were found in the grafting site, in the RMS and in the OB 14 days after transplantation (fig. 5F, G \& table 3). Thus, iron-labeled rNSC migrated in a similar way than endogeneous rNSC in the absence of lesion. 


\section{DISCUSSION}

Potential adverse effects of iron nanoparticles is a topic currently under investigation [35], and the means to diminish this side effect still remain to be explored. Many authors described the use of facilitating agents [2] such as lipofectamin [16], conjugation with Tat peptide [26] or with internalizing antibodies [7] to increase the uptake efficiency while diminishing cell toxicity. However, these methods are also currently under debate [4] and transfecting agents may not be approved for clinical use [29]. In our study, we demonstrated an efficient and non toxic in vitro uptake of native HEDP-coated SPIO nanoparticles by rMSC without using any transfecting agent. In addition, the bisphosphonate (HEDP) coating offers the possibility to functionalize the nanoparticles, therefore increasing the range of potential applications.

Forty-eight hours incubation with $50 \mu \mathrm{g}$ iron/mL of these SPIO nanoparticles was the best tradeoff in terms of labeling efficiency and cell viability. Under the conditions used, more than $90 \%$ of the rMSC contained enough iron allowing their detection with PB staining; amount that is in the same range than what is usually described e.g. with D-mannose-coated nanoparticles where $80 \%$ of the cells were labeled [43]. An efficient uptake is indeed required as a simple adhesion on the cell surface could be detrimental for the cell response to the microenvironment in vivo [43]. In this regard, we confirmed the endocytosis of the iron nanoparticles by SEM and TEM studies. In our study, the average iron content per cell $(5.6 \pm 1.6 \mathrm{pg})$ was low compared to what is described with polycation-bound SPIO nanoparticles (38 pg iron/cell) [43], but in the same range to what is obtained when labeling human MSC with the ferucarbotran Resovist ${ }^{\circledR}[29]$.

In addition to an absence of acute toxicity, the HEDP-coated nanoparticles had no significant side effects on rMSC behavior in vitro. The ultrastructure was conserved and their differentiation potential toward the osteogenic as well as neuronal lineages did not exhibit significant differences with unlabeled rMSC. MSC differentiation toward a neuronal-like lineage is now well-documented $[5,39,44,46]$ and the fraction of differentiating rMSC (50 to $65 \%)$ confirmed results published with this 
protocol [49]. Interestingly, NeuN was always detected in the rMSC used in this study. In this regard, the expression of neuronal markers in expanding, uninduced MSC has already been described [45]. These results complement previous studies which described a conserved adipogenic and osteogenic differentiation potential $[3,14]$ even if chondrogenic differentiation was sometimes impaired with Feridex ${ }^{\circledR}$ nanoparticles [24]. Altogether, these results confirmed the possible use of the HEDP-coated nanoparticles for cell tracking as it does not seem to interfere with the in vitro rMSC biology. Moreover, trials made to label a subpopulation of human MSC, the MIAMI cells [12] showed that they readily absorbed HEDP-coated iron nanoparticles, even with a higher efficiency than rMSC (data not shown). As MIAMI cells present a large differentiation potential, including the ectodermal lineage, this may render possible their future use for MRI tracking in human clinical cell therapy applications [44].

In vivo, a double staining PB/CD11b (specific for macrophage/microglia) demonstrated that CD11b-positive cells did not, for the most part, co-localize with PB staining and therefore gave the proof that uptake by the host immune system is limited. Similar results with PB/ED1 double staining were obtained with rMSC containing dextran-coated Endorem® nanoparticles in a spinal cord injury model [41]. To our knowledge, this phenomenon has not been previously described in other cell types, suggesting that this event may be cell dependent. Therefore, the fate of iron nanoparticles will have to be addressed in more details in future studies using MSC. On the other hand, a possible transfer of BrdU to the host cells 3 weeks after transplantation has been described [8], but as BrdU labeling co-localized nicely with PB in our study, it suggests that the majority of detected cells were iron-containing rMSC and not host cells.

Iron-labeled rMSC did not respond to the microenvironmental stimuli when stereotactically implanted into the SVZ and did not migrate toward the OB via the RMS. However, when transplanted in the SVZ of a rat brain presenting a mechanical injury of the $\mathrm{OB}$, the iron-labeled rMSC extensively migrated from the grafting site to the OB through the RMS, therefore covering a distance of approximately $7 \mathrm{~mm}$. Indeed, rMSC were easily detected by BrdU IHC and PB staining all over the 
migratory pathway 14 days post-transplantation when a sufficient amount of cells $\left(80 \times 10^{3}\right)$ was injected. The fainter staining observed by IHC after 21 days may result from a possible cell proliferation, and therefore from an iron dilution, as was described for MSC transplanted in a brain infarct model 3 months after transplantation [50]. Using MRI, the fraction of rMSC migrating toward the OB was not detected as the mechanical lesion induced a very important background hyposignal. Therefore, precautions will have to be taken in studies seeking to visualize iron-labeled cells in similar lesioned environments. It is of importance to note that we did not observe any adverse effect on the behaviour of the animals even 21 days post-transplantation. Moreover, no signs of toxicity were detected by use of current histological staining (hematoxilin/eosin), therefore confirming the safety of SPIO nanoparticles for in vivo applications [33].

Taken together, these in vivo results demonstrate that $\mathrm{rMSC}$ were not able to migrate in a similar fashion than rNSC when transplanted into the SVZ of a normal brain, but did confirm their known potential to be attracted by lesions, even after iron-loading [20,42,50]. It underlines the importance of the microenvironment on rMSC migratory behavior. Indeed, without lesion, in opposition to rMSC, neurosphere-derived iron-labeled rNSC, used as a positive control for cell migration, did respond to the SVZ niche stimuli and demonstrate an important migratory potential toward the OB through the RMS. This confirmed previous studies using labeled rat NSC [10], unlabeled NSC [13,17] as well as labeled human NSC [18]. The migratory response of MSC to appropriate adhesion or inflammatory molecules and to chemokines present in damaged tissues is now well documented [36,40]. Indeed, many chemoattractive molecules present in a lesioned environment, including for example the monocyte chemoattractant protein-1 (MCP-1), the macrophage inflammatory protein $1 \alpha(\mathrm{MIP}-1 \alpha)$ and IL-8 [47], are known to promote cell migration via an interaction with MSC cell surface receptors. Therefore, we assumed it was the underlying mechanism leading the migration of rMSC observed in the presence of an OB lesion. However, the migration in a normal adult brain of a MSC subpopulation expressing receptors known to regulate neural cell activity and migration in brain has been reported [37]. However, MSC are 
a heterogenous population so these receptors, including Neo1, Nrp2 and Robo1 \& 4, may not be present on the rMSC used in this study as we did not observe any migration in an undamaged brain. Similarly to Phinney et al. [37], we may hypothesize that MSC migrating in an inflammatory environment are a different subpopulation from those that migrate in response to guidance cues modulating neural cell migration.

As a conclusion, HEDP-coated SPIO nanoparticles were used to efficiently label rMSC without impairing cell viability and structure, as well as their differentiation potentials toward the osteogenic and neuronal lineages. In vivo, iron-labeled rMSC migration toward the OB was not induced by the SVZ microenvironment. However, their well-known capacity to migrate toward lesions was confirmed as they extensively migrated toward a mechanically injured OB. Moreover, a double staining for macrophage/microglia and iron-containing cells confirmed that the majority of detected cells were not host cells. To the best of our knowledge, this was the first time that a long distance migration from the SVZ toward a lesioned OB through the RMS was described for iron-labeled rMSC. This conserved ability to migrate in vivo when stimulated by a lesion, in addition to their differentiation potential, underlines once again the possible benefits of using mesenchymal stem cells for brain cell therapy. 


\section{EXPERIMENTAL PROCEDURE}

All animal experiments were conducted in accordance with the "Direction des Services Vétérinaires", the "Ministère de l'Agriculture" of France and with the European Communities Council Directive of 24 November 1986 (86/609/EEC).

\section{Isolation and culture of MSC}

To obtain rMSC, tibias and femurs of $250 \mathrm{~g}$ female Sprague Dawley rats (Charles River, l'Arbresle, France) were dissected. Bone marrow was harvested by flushing the medullar cavities using a 26-gauge needle with $4 \mathrm{ml}$ of Dulbecco's modified Eagle's medium high glucose (DMEM-HG) (Lonza, Levallois-Perret, France) containing $2 \mathrm{mM}$ L-glutamine and antibiotics (100 U/mL penicillin, $0.1 \mathrm{mg} / \mathrm{mL}$ streptomycin, $0.25 \mu \mathrm{g} / \mathrm{mL}$ amphotericin B, Sigma, St Quentin Fallavier, France). Cells were plated at a density of $2 \times 10^{6}$ cells $/ \mathrm{cm}^{2}$ in DMEM low glucose (DMEM-LG) (Lonza) containing $20 \%$ foetal bovine serum (FBS) (Lonza) and antibiotics. All cell cultures were performed at $37^{\circ} \mathrm{C}$ in a humidified $5 \% \mathrm{CO}_{2}$ atmosphere. After $24 \mathrm{~h}, \mathrm{MSC}$ were selected by removing the non-adherent cells. Fourteen days later, adherent cells were detached with $0.25 \%$ trypsin-EDTA (Sigma) and plated at 2000 cells $/ \mathrm{cm}^{2}$. Medium was changed twice a week and cells re-plated when at $70 \%$ confluency.

\section{Isolation and culture of rNSC}

Cortex from E14-15 Sprague Dawley rat embryos were dissected, cut into small pieces and finally triturated using a firepolished Pasteur pipette. Neurospheres were formed by culturing in $3 \mathrm{v}$ DMEM-HG, 1v Ham's F12 (Lonza) supplemented with B27 (GIBCO, Cergy-Pontoise, France), 20 ng/ml EGF, 20 ng/ml bFGF (R\&D Systems Europe, Lille, France), $5 \mu \mathrm{g} / \mathrm{ml}$ heparin (Sigma) and antibiotics. Cells were fed every 2 or 3 days and split every 5 days at 1:3 dilution. Large neurospheres were cut with micro-scissors. Adherent neural progenitors were cultured with the same media in poly-D- 
lysine (Sigma) coated plates $(100 \mu \mathrm{g} / \mathrm{mL}$ poly-D-lysine in Dulbecco's phosphate buffered saline, DPBS, Lonza).

\section{Synthesis of HEDP-coated SPIO nanoparticles}

SPIO nanoparticles were prepared and purified as previously described [38]. Briefly, bare iron cores were generated under agitation by the coprecipitation of an aqueous solution of $100 \mu \mathrm{LFe}_{2} \mathrm{Cl}_{2}$ $(0.314 \mathrm{M})$ and $100 \mu \mathrm{L} \mathrm{Fe}_{3} \mathrm{Cl}_{3}(0.666 \mathrm{M})$ in $2.5 \mathrm{~mL}$ of a $1 \mathrm{M}$ tetramethylammonium hydroxide solution (all from Sigma). After 3 minutes, the $4 \mathrm{~nm}$ bare iron particles were incubated for $20 \mathrm{~min}$ at $20^{\circ} \mathrm{C}$ with $48 \mu \mathrm{M}$ 1-hydroxyethylidene-1.1-bisphosphonic acid (HEDP) (Sigma). The $\mathrm{pH}$ of the solution was lowered to 6.0 using $3 \mathrm{M}$ tetraethylsulfamide (Sigma) to allow for HEDP adsorption on the bare cores. After incubation, the nanoparticles were purified on a $20 \mathrm{~cm}$ Biogel P6 column (BioRad, Marnes-laCoquette, France) at room temperature (RT). This resulted in a solution of HEDP-coated SPIO nanoparticles with a hydrodynamic diameter of $20 \mathrm{~nm}$ and a final iron concentration of $0.8 \mathrm{~g} / \mathrm{L}$. Magnetic relaxivities of those nanoparticles at $7 \mathrm{~T}$ were: $\mathrm{r} 1=1 \mathrm{mM}^{-1} \mathrm{~s}^{-1}$ and $\mathrm{r} 2=50 \mathrm{mM}^{-1} \mathrm{~s}^{-1}[32]$.

\section{Nanoparticle uptake and cell characterization}

Iron labeling. Nanoparticles were added to the culture medium at a concentration of 25,50 or $100 \mu \mathrm{g}$ iron/mL for 24 or 48 hours after the rMSC reached $60 \%$ confluency. Fugene $^{\circledR}$ (Roche, Meylan, France) transfection agent was tested to decrease the incubation time with nanoparticles: $1 \mu \mathrm{L} / \mathrm{mL}$ Fugene ${ }^{\circledR}$ was added to DMEM containing nanoparticles for $30 \mathrm{~min}$ before incubation with the cells in culture.

Cell viability. It was estimated by Trypan blue (Sigma) exclusion and by an MTS assay kit (Promega, Charbonnières-les-Bains, France). Briefly, after washing the cells with DPBS and incubation with diluted (1:5) MTS reagent for $4 \mathrm{~h}$, samples were read at $490 \mathrm{~nm}$ by use of a Multiskan ascent spectrophotometer (Thermo Fisher scientific, Cergy Pontoise, France). 
Prussian blue (PB) staining. Cells were fixed in $4 \%$ paraformaldehyde (PFA) (Sigma) for 15 min at $4^{\circ} \mathrm{C}$, washed with DPBS and incubated 20 min with Pearl's reagent. Reagent was extemporaneously prepared: $1 \%$ potassium ferrocyanide in $3 \% \mathrm{HCl}(\mathrm{Sigma})$, heated for $20 \mathrm{~min}$ at $60^{\circ} \mathrm{C}$ and filtered. Cells were counterstained with $1 \%$ eosin, washed with $1 \%$ acetic acid (Sigma) before dehydration and mounting (Eukitt) (Labonord, Templemars, France). Cells were examined under bright field using an Axioscop microscope (Carl Zeiss, Le Pecq, France), a CoolSnap ES camera (Photometrics, Tucson, Arizona) and Metavue analysis software (Roper Scientific, Evry, France).

Quantitative intracellular iron content assessment. The average iron content of rMSC was assessed after incubation using inductively coupled plasma optical emission spectroscopy. $5 \times 10^{5}$ cells were incubated with $65 \%$ (v/v) nitric acid for $2 \mathrm{~h}$. Cell extracts were diluted in water and the total iron content was measured at $260 \mathrm{~nm}$ using a Jobin-Yvon 238 ICP-OES spectroscope (Ultrace Instruments SA, Longjumeau, France).

TEM. Iron intracellular localization was confirmed by TEM. Cells were fixed for $30 \mathrm{~min}$ in $2 \%$ glutaraldehyde in DPBS, then washed with DPBS, post-fixed in $2 \%$ osmium tetroxide in DPBS for $1 \mathrm{~h}$, and washed again before dehydration with ethanol (Sigma). After exposure to propylene oxide (Sigma), samples were infiltrated in $100 \%$ epon resin and polymerized in a $60^{\circ} \mathrm{C}$ oven for $48 \mathrm{~h}$. Samples were sectioned using a diamond knife on an Ultracut-S ultramicrotome (Leica Microsystems, RueilMalmaison, France). $70 \mathrm{~nm}$ sections were picked up on copper grids, contrasted with uranyl acetate (Merck, Fontenay Sous Bois, France) and Pb nitrate (Merck) solutions and coated with carbon. Sections were examined with a Jeol 2011 transmission electron microscope at $140 \mathrm{kV}$ (Jeol, Croissy sur Seine, France).

SEM. Cells were fixed with $2 \%$ glutaraldehyde (Sigma), dehydrated with increasing concentrations of ethanol and desiccated with hexamethyldisilazane (Carl Roth, Lauterbourg, France). Samples were finally coated with carbon and examined with a Jeol 6301F scanning electron microscope 
at $11 \mathrm{kV}$ for backscattered images. EDX analysis was performed to confirm the iron nature of the observed nanoparticles.

In vitro MRI. After incubation with the SPIO nanoparticles, cells were washed, trypsinized and centrifuged. Cells were then embedded in a low melting-point $0.5 \%$ agarose type VII (Sigma) gel at a concentration of 1 cell/voxel. MRI experiments were performed on a Bruker Avance DRX 300 system (Bruker Biospin, Wissembourg, France) equipped with a $150 \mathrm{~mm}$ vertical super-widebore magnet operating at $7 \mathrm{~T}$, an $84 \mathrm{~mm}$ i.d. shielded gradient set capable of $144 \mathrm{mT} / \mathrm{m}$ maximum gradient strength and a standard $64 \mathrm{~mm}$ diameter birdcage resonator, operating on a Paravision software platform (version 2.1.1, Bruker Biospin). A 3D spoiled gradient-echo sequence (TR=110 ms; FOV 30*30*15 mm; matrix $128 * 128 * 32, \alpha=20^{\circ}$ ), modified to a multi-echo sequence ( $\mathrm{TE}=5 \mathrm{~ms}, \mathrm{IE}=5 \mathrm{~ms}$, nEchos $=6$ ) was used for quantitative $\mathrm{T} 2 *$ mapping [15].

Osteogenic differentiation. rMSC were plated at a density of 5500 cells $/ \mathrm{cm}^{2}$ in DMEM-HG containing $10 \%$ FBS, $10 \mathrm{mM} \beta$-glycerol-phosphate, $50 \mathrm{mM}$ ascorbate-2-phosphate, $100 \mathrm{nM}$ dexamethason and antibiotics (Sigma). Medium was changed twice a week during 21 days. Cells were washed 3 times with DPBS and fixed with ice-cold $70^{\circ}$ ethanol for 1 hour at $4^{\circ} \mathrm{C}$. Staining was performed by 10 min incubation with $40 \mathrm{mM}$ Alizarin Red-S (Sigma), pH 4.2 at RT. Cells were finally washed with DPBS and samples examined using an Axiovert 40 CFL bright-field microscope (Carl Zeiss).

Neuronal differentiation. Neuronal induction was performed according to a previously described protocol [49]. Briefly, rMSC were plated at $10 \times 10^{3}$ cells $/ \mathrm{cm}^{2}$ on $0.5 \mu \mathrm{g} / \mathrm{cm}^{2}$ fibronectin (Sigma) coated coverslips in DMEM-HG containing 20 \% FBS and antibiotics. Neuronal pre-induction medium, consisting of DMEM-HG containing $20 \%$ FBS and $1 \mathrm{mM} \beta$-mercaptoethanol (Sigma), was added for 24 hours. Afterwards, cells were washed with DPBS and transferred to neuronal induction media composed of DMEM-HG, $2 \%$ dimethylsulfoxide (DMSO) (Sigma) and $200 \mu$ M butylated 
hydroxyanisole (Sigma). Uninduced cells and cells exposed to the induction medium for 24 hours and 48 hours were stained for nestin, $\beta 3$-tubulin and NeuN to assess the extent of neuronal differentiation. After washing with DPBS, cells were fixed with $4 \%$ PFA at $4^{\circ} \mathrm{C}$ for $15 \mathrm{~min}$, permeabilized with $0.2 \%$ Triton X-100 (Sigma) for 5 min and blocked with DPBS, $10 \%$ normal goat serum (Sigma), $4 \%$ bovine serum albumin (BSA) (Sigma) at RT for 45 min. After washing with DPBS, the cells were then incubated overnight at $4^{\circ} \mathrm{C}$ with $5 \mu \mathrm{g} / \mathrm{mL}$ anti-nestin (BD Biosciences, Le Pont De Claix, France), 3.8 $\mu \mathrm{g}$ IgG2b/mL anti- $\beta 3$-Tubulin (Sigma) or $20 \mu \mathrm{g} / \mathrm{mL}$ anti-NeuN (Chemicon, St Quentin en Yvelines, France) monoclonal mouse antibodies in DPBS, 4 \% BSA, $0.2 \%$ Triton X-100. After washing with DPBS, incubation with $2.5 \mu \mathrm{g} / \mathrm{mL}$ secondary biotinylated anti-mouse antibody (Ref BA2001, Abcys, Paris, France) in DPBS, 4 \% BSA, $0.2 \%$ Triton X-100 was performed for 1 hour at RT. Finally, after washing with DPBS, incubation with $20 \mu \mathrm{g} / \mathrm{mL}$ streptavidin FITC (Ref F0422, Dako, Trappes, France) in DPBS for 40 min at RT was made before mounting (Fluorescent mounting medium, Dako) and observation under fluorescence microscopy (Axioscop, Carl Zeiss). Isotype controls were performed.

\section{Labeling methods for histochemical detection}

Hoechst 33342 labeling. After washing, cells were resuspended in $1 \mathrm{ml}$ DMEM-HG containing $10 \mathrm{mg} / \mathrm{mL}$ Hœchst (Sigma), left for $30 \mathrm{~min}$ at $37^{\circ} \mathrm{C}$ and finally washed again 3 times.

PKH26 labeling. Cells were washed and resuspended in $500 \mu 1$ DMEM-HG before adding 1.5 $\mu \mathrm{L}$ PKH26 (Sigma) for 3 min. Excess label was washed away with FBS, then washed again with DPBS 4 times. Co-cultures of $\mathrm{GFP}^{+}$cells and Hoechst or PKH26-labeled cells were performed for 24-72 hours in order to evaluate the diffusion of the fluorescent dye to neighbouring cells. Cells were finally washed with DPBS and samples examined by fluorescence microscopy.

Lentiviral transduction of GFP. TEFLYGA (Gabon ape) human cell line containing a simian retrovirus encoding GFP with a CMV promoter was used for virus production (kind gift from Dr JC. 
Pagès). Infection was performed with $5 \mu \mathrm{g} / \mathrm{ml}$ Polybrene ${ }^{\circledR}$ (Sigma) and $\mathrm{GFP}^{+}$cells were selected with $500 \mu \mathrm{g} / \mathrm{ml}$ Neomycin G418 (Sigma) for 7 to 10 days.

BrdU labeling. rMSC and rNSC were incubated with $1 \mu \mathrm{L} / \mathrm{mL}$ BrdU from a BrdU Immunofluorescence Assay Kit (Roche Diagnostics, Meylan, France) on a time scale ranging from 6 to $96 \mathrm{~h}$. For the rapidly dividing rNSC, shorter incubation times of 6 and 24 hours were tested and the uptake efficiency was compared between floating neurospheres and adherent neural progenitors. BrdU uptake was assessed by immunofluorescent staining following the Immunofluorescence Assay Kit instructions. After BrdU labeling, rMSC and rNSC were seeded on fibronectin and poly-D-lysine-coated coverslips respectively, washed with DPBS and fixed with $4 \%$ PFA in DPBS for 10 min at $4{ }^{\circ} \mathrm{C}$. After washing, cells were incubated with the primary anti-BrdU mouse antibody (1:20) (Clone BMG 6H8) for $30 \mathrm{~min}$. The secondary anti-mouse fluorescein-conjugated antibody (1:20) was added for $30 \mathrm{~min}$ at $37^{\circ} \mathrm{C}$. Mounting and observations were performed as described in the previous section.

\section{Cell transplantation}

A total number of 50 ten weeks old Sprague-Dawley female rats of $220 \mathrm{~g}$ were anesthetized with 16 mg/kg Xylasin (Rompun ${ }^{\circledR}$, Bayer, Puteaux, France) and 80 mg/kg Ketamine (Clorketam $1000^{\circledR}$, Vétoquinol, Lure, France). Prior to transplantation, rMSC were incubated for at least 72 hours with BrdU and the SPIO nanoparticles were added to the medium during the last 48 hours of incubation. rNSC (adherent neural progenitors) were incubated for 48 hours with the SPIO nanoparticles and BrdU was added during the last 6 hours of incubation. After labeling, $40 \times 10^{3}$ to $100 \times 10^{3} \mathrm{rMSC}$ or rNSC were injected in a final volume of DMEM-HG ranging from 2 to $5 \mu \mathrm{L}$ using a $10 \mu 1$ microsyringe (Hamilton, Reno, Nevada). The injection was performed at a rate of $2 \mu \mathrm{L} / \mathrm{min}$ and the cannula was kept in situ for an additional 4 min before withdrawal. Control rats received an equivalent volume of DMEM-HG only or unlabeled cells. Injection coordinates were chosen in the SVZ, close to the beginning of the RMS: $+0.9 \mathrm{~mm}$ rostral to Bregma, $-1.2 \mathrm{~mm}$ lateral to the midline, $-3.9 \mathrm{~mm}$ ventral to the dura and the tooth bar 


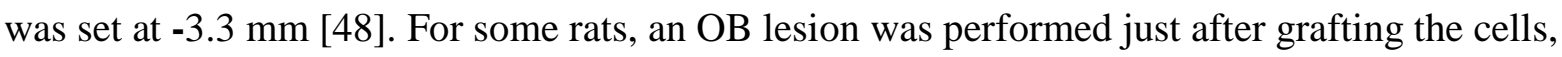
ipsilaterally to the injection site at $6.5 \mathrm{~mm}$ from Bregma, using a $3 \mathrm{~mm}$ diameter drill.

\section{In vivo immunohistochemical tracking}

Four, 14 and 21 days after transplantation, rats were anesthetized by $\mathrm{CO}_{2}$ inhalation. $0.9 \% \mathrm{NaCl}$ and $4 \%$ PFA were used sequentially for intracardial perfusion and brains were left in PFA containing increasing amounts of sucrose (from 2.5 to $20 \%$ ) (all from Sigma). Brain sections of $14 \mu$ m were made on a CM 3050S cryotome (Leica Microsystems). IHC was used in vivo for the detection of BrdU ${ }^{+}$cells and a mouse anti-CD11b antibody (specific for macrophage-microglia) was used to assess the inflammatory reaction. For BrdU staining, sections were washed with DPBS and incubated for 2 hours at $65^{\circ} \mathrm{C}$ in $\mathrm{SSC}$ buffer (1v sodium chloride-sodium citrate $\mathrm{pH} 7.4,1 \mathrm{v}$ formamide), 30 min with $2 \mathrm{~N} \mathrm{HCl}$ in DPBS at $37^{\circ} \mathrm{C}$ and finally $10 \mathrm{~min}$ in $0.1 \mathrm{M}$ sodium borate, $\mathrm{pH} 8.5$ at $\mathrm{RT}$ (all from Sigma). Quenching of peroxidases was made with $3 \% \mathrm{H}_{2} \mathrm{O}_{2}$ (Sigma) in DPBS at RT for $15 \mathrm{~min}$. For BrdU and CD11b staining, blocking was performed overnight at $4^{\circ} \mathrm{C}$ or 40 min at RT, respectively. BrdU blocking buffer: DPBS, $3 \%$ BSA, $0.1 \%$ Tween 20 (Sigma). CD11b blocking buffer: DPBS, $10 \%$ normal goat serum, 4 $\%$ BSA, $0.2 \%$ Triton-X 100. Sections were incubated with the rat anti-BrdU antibody (1:100) (Ref OBT0030, clone BU1/75 ICR1) for 4 hours at RT and with the mouse anti-CD11b antibody (1:50) (Ref MCA275G, clone MRC OX-42) overnight at $4^{\circ} \mathrm{C}$ (both from Abd Serotec, Cergy Saint-Christophe, France). After washing, sections were incubated at RT for 2 hours with the secondary biotinylated antirat (1:200) (Ref BA4001) or for 1 hour with the anti-mouse antibodies (1:200) (Ref BA2001). BrdU incubation buffer: DPBS, $1 \%$ BSA, $0.1 \%$ Tween 20. CD11b incubation buffer: DPBS, $4 \%$ BSA, $0.2 \%$ Triton-X 100. Incubation with Vectastain ${ }^{\circledR}$ ABC reagent in $0.1 \%$ Tween 20 in DPBS was made at RT (1.5 hours for BrdU and 1 hour for CD11b) (all from Abcys). Sections were washed and revealed with $0.03 \% \mathrm{H}_{2} \mathrm{O}_{2}, 2 \mathrm{mg} / \mathrm{mL}$ diaminobenzidine (DAB) (Sigma) (supplemented with $0.16 \%$ nickel chloride hexahydrate (Sigma) for BrdU), in DPBS for 10 min at RT and washed before mounting. 
For PB/CD11b double staining, sections were fixed again with $2 \%$ PFA in DPBS for 5 min at $4^{\circ} \mathrm{C}$ after CD11b staining. Staining with Pearl's reagent was then performed as previously described and samples were examined by bright field microscopy.

\section{In vivo MRI tracking}

In vivo, MRI was performed under the conditions defined for in vitro study. A TE $=10 \mathrm{~ms}$ was chosen as it allowed to depict microscopic susceptibility inhomogeneities induced by SPIOs without jeopardizing the overall image quality by macroscopic susceptibility artefacts. During the in vivo imaging process, animals were anaesthetized using a mixture of isoflurane $/ \mathrm{O}_{2}(1.5 \%, 2 \mathrm{~L} / \mathrm{min})$ and body temperature was maintained at $36.5-37.5^{\circ} \mathrm{C}$ using a feedback-regulated heating pad. 


\section{ACKNOWLEDGMENTS}

We would like to thank the SCIAM (Service Commun d'Imagerie et d'Analyse Microscopique, Angers, France) for electron microscopy imaging and the toxicology department of the hospital of Angers (Angers, France) for iron spectroscopic titration.

We would also like to thank the "Région Pays de la Loire" for financial support.

Finally, we are grateful to Pr JC. Pagès (INSERM ERI 19, faculté de médecine, Tours, France) for providing the GFP lentiviral vector and to Pr PC. Schiller (Department of Medecine, University of MIAMI School of medicine, MIAMI, Florida, USA) for the use of MIAMI cells. 


\section{LITERATURE REFERENCES}

[1] K.S. Aboody, A. Brown, N.G. Rainov, K.A. Bower, S. Liu, W. Yang, J.E. Small, U. Herrlinger, V. Ourednik, P.M. Black, X.O. Breakefield and E.Y. Snyder, Neural stem cells display extensive tropism for pathology in adult brain: evidence from intracranial gliomas, Proc Natl Acad Sci U S A 97 (2000) 12846-12851.

[2] A.S. Arbab, L.A. Bashaw, B.R. Miller, E.K. Jordan, J.W. Bulte and J.A. Frank, Intracytoplasmic tagging of cells with ferumoxides and transfection agent for cellular magnetic resonance imaging after cell transplantation: methods and techniques, Transplantation 76 (2003) 1123-1130.

[3] A.S. Arbab, G.T. Yocum, A.M. Rad, A.Y. Khakoo, V. Fellowes, E.J. Read and J.A. Frank, Labeling of cells with ferumoxides-protamine sulfate complexes does not inhibit function or differentiation capacity of hematopoietic or mesenchymal stem cells, NMR Biomed 18 (2005) 553-559. [4] A.S. Arbab, G.T. Yocum, L.B. Wilson, A. Parwana, E.K. Jordan, H. Kalish and J.A. Frank, Comparison of transfection agents in forming complexes with ferumoxides, cell labeling efficiency, and cellular viability, Mol Imaging 3 (2004) 24-32.

[5] I.B. Black and D. Woodbury, Adult rat and human bone marrow stromal stem cells differentiate into neurons, Blood Cells Mol Dis 27 (2001) 632-636.

[6] J.W. Bulte, I.D. Duncan and J.A. Frank, In vivo magnetic resonance tracking of magnetically labeled cells after transplantation, J Cereb Blood Flow Metab 22 (2002) 899-907.

[7] J.W. Bulte, S. Zhang, P. van Gelderen, V. Herynek, E.K. Jordan, I.D. Duncan and J.A. Frank, Neurotransplantation of magnetically labeled oligodendrocyte progenitors: magnetic resonance tracking of cell migration and myelination, Proc Natl Acad Sci U S A 96 (1999) 15256-15261.

[8] T.C. Burns, X.R. Ortiz-Gonzalez, M. Gutierrez-Perez, C.D. Keene, R. Sharda, Z.L. Demorest, Y. Jiang, M. Nelson-Holte, M. Soriano, Y. Nakagawa, M.R. Luquin, J.M. Garcia-Verdugo, F. Prosper, W.C. Low and C.M. Verfaillie, Thymidine analogs are transferred from prelabeled donor to host cells in the central nervous system after transplantation: a word of caution, Stem Cells 24 (2006) 1121-1127. 
[9] X. Chen, Y. Li, L. Wang, M. Katakowski, L. Zhang, J. Chen, Y. Xu, S.C. Gautam and M.

Chopp, Ischemic rat brain extracts induce human marrow stromal cell growth factor production, Neuropathology 22 (2002) 275-279.

[10] F. Cicchetti, R.E. Gross, J.W. Bulte, M. Owen, I. Chen, M. Saint-Pierre, X. Wang, M. Yu and A.L. Brownell, Dual-modality in vivo monitoring of subventricular zone stem cell migration and metabolism, Contrast Media Mol Imaging 2 (2007) 130-138.

[11] V. Coskun and M.B. Luskin, Intrinsic and extrinsic regulation of the proliferation and differentiation of cells in the rodent rostral migratory stream, J Neurosci Res 69 (2002) 795-802.

[12] G. D'Ippolito, S. Diabira, G.A. Howard, P. Menei, B.A. Roos and P.C. Schiller, Marrow-isolated adult multilineage inducible (MIAMI) cells, a unique population of postnatal young and old human cells with extensive expansion and differentiation potential, J Cell Sci 117 (2004) 2971-2981.

[13] U. Englund, R.A. Fricker-Gates, C. Lundberg, A. Bjorklund and K. Wictorin, Transplantation of human neural progenitor cells into the neonatal rat brain: extensive migration and differentiation with long-distance axonal projections, Exp Neurol 173 (2002) 1-21.

[14] E. Farrel, P. Wielopolski, P. Pavljasevic, S. van Tiel, H. Jahr, J. Verhaar, H. Weinans, G. Krestin, F.J. O'Brien, G. van Osch and M. Bernsen, Effects of iron oxide incorporation for long term cell tracking on MSC differentiation in vitro and in vivo, Biochem Biophys Res Commun (2008).

[15] F. Franconi, P. Mowat, L. Lemaire, P. Richomme and J.J. Le Jeune, Single-scan quantitative T2* methods with susceptibility artifact reduction, NMR Biomed 19 (2006) 527-534.

[16] J.A. Frank, B.R. Miller, A.S. Arbab, H.A. Zywicke, E.K. Jordan, B.K. Lewis, L.H. Bryant, Jr. and J.W. Bulte, Clinically applicable labeling of mammalian and stem cells by combining superparamagnetic iron oxides and transfection agents, Radiology 228 (2003) 480-487.

[17] R.A. Fricker, M.K. Carpenter, C. Winkler, C. Greco, M.A. Gates and A. Bjorklund, Site-specific migration and neuronal differentiation of human neural progenitor cells after transplantation in the adult rat brain, J Neurosci 19 (1999) 5990-6005. 
[18] R. Guzman, N. Uchida, T.M. Bliss, D. He, K.K. Christopherson, D. Stellwagen, A. Capela, J. Greve, R.C. Malenka, M.E. Moseley, T.D. Palmer and G.K. Steinberg, Long-term monitoring of transplanted human neural stem cells in developmental and pathological contexts with MRI, Proc Natl Acad Sci U S A 104 (2007) 10211-10216.

[19] C. Heyn, J.A. Ronald, L.T. Mackenzie, I.C. MacDonald, A.F. Chambers, B.K. Rutt and P.J. Foster, In vivo magnetic resonance imaging of single cells in mouse brain with optical validation, Magn Reson Med 55 (2006) 23-29.

[20] P. Jendelova, V. Herynek, L. Urdzikova, K. Glogarova, J. Kroupova, B. Andersson, V. Bryja, M. Burian, M. Hajek and E. Sykova, Magnetic resonance tracking of transplanted bone marrow and embryonic stem cells labeled by iron oxide nanoparticles in rat brain and spinal cord, J Neurosci Res 76 (2004) 232-243.

[21] Y. Jiang, B.N. Jahagirdar, R.L. Reinhardt, R.E. Schwartz, C.D. Keene, X.R. Ortiz-Gonzalez, M. Reyes, T. Lenvik, T. Lund, M. Blackstad, J. Du, S. Aldrich, A. Lisberg, W.C. Low, D.A. Largaespada and C.M. Verfaillie, Pluripotency of mesenchymal stem cells derived from adult marrow, Nature 418 (2002) 41-49.

[22] Z. Kokaia and O. Lindvall, Neurogenesis after ischaemic brain insults, Curr Opin Neurobiol 13 (2003) 127-132.

[23] G.C. Kopen, D.J. Prockop and D.G. Phinney, Marrow stromal cells migrate throughout forebrain and cerebellum, and they differentiate into astrocytes after injection into neonatal mouse brains, Proc Natl Acad Sci U S A 96 (1999) 10711-10716.

[24] L. Kostura, D.L. Kraitchman, A.M. Mackay, M.F. Pittenger and J.W. Bulte, Feridex labeling of mesenchymal stem cells inhibits chondrogenesis but not adipogenesis or osteogenesis, NMR Biomed 17 (2004) 513-517. 
[25] K. Le Blanc, C. Tammik, K. Rosendahl, E. Zetterberg and O. Ringden, HLA expression and immunologic properties of differentiated and undifferentiated mesenchymal stem cells, Exp Hematol 31 (2003) 890-896.

[26] M. Lewin, N. Carlesso, C.H. Tung, X.W. Tang, D. Cory, D.T. Scadden and R. Weissleder, Tat peptide-derivatized magnetic nanoparticles allow in vivo tracking and recovery of progenitor cells, Nat Biotechnol 18 (2000) 410-414.

[27] Y. Li, J. Chen, X.G. Chen, L. Wang, S.C. Gautam, Y.X. Xu, M. Katakowski, L.J. Zhang, M. Lu, N. Janakiraman and M. Chopp, Human marrow stromal cell therapy for stroke in rat: neurotrophins and functional recovery, Neurology 59 (2002) 514-523.

[28] A. Mahmood, D. Lu, L. Wang and M. Chopp, Intracerebral transplantation of marrow stromal cells cultured with neurotrophic factors promotes functional recovery in adult rats subjected to traumatic brain injury, J Neurotrauma 19 (2002) 1609-1617.

[29] V. Mailander, M.R. Lorenz, V. Holzapfel, A. Musyanovych, K. Fuchs, M. Wiesneth, P. Walther, K. Landfester and H. Schrezenmeier, Carboxylated Superparamagnetic Iron Oxide Particles Label Cells Intracellularly Without Transfection Agents, Mol Imaging Biol (2008).

[30] B. Maitra, E. Szekely, K. Gjini, M.J. Laughlin, J. Dennis, S.E. Haynesworth and O.N. Koc, Human mesenchymal stem cells support unrelated donor hematopoietic stem cells and suppress T-cell activation, Bone Marrow Transplant 33 (2004) 597-604.

[31] M. Modo, D. Cash, K. Mellodew, S.C. Williams, S.E. Fraser, T.J. Meade, J. Price and H. Hodges, Tracking transplanted stem cell migration using bifunctional, contrast agent-enhanced, magnetic resonance imaging, Neuroimage 17 (2002) 803-811.

[32] P. Mowat, F. Franconi, C. Chapon, L. Lemaire, J. Dorat, F. Hindre, J.P. Benoit, P. Richomme and J.J. Le Jeune, Evaluating SPIO-labelled cell MR efficiency by three-dimensional quantitative T2* MRI, NMR Biomed 20 (2007) 21-27. 
[33] L.L. Muldoon, M. Sandor, K.E. Pinkston and E.A. Neuwelt, Imaging, distribution, and toxicity of superparamagnetic iron oxide magnetic resonance nanoparticles in the rat brain and intracerebral tumor, Neurosurgery 57 (2005) 785-796; discussion 785-796.

[34] A. Nasef, N. Mathieu, A. Chapel, J. Frick, S. Francois, C. Mazurier, A. Boutarfa, S. Bouchet, N.C. Gorin, D. Thierry and L. Fouillard, Immunosuppressive effects of mesenchymal stem cells: involvement of HLA-G, Transplantation 84 (2007) 231-237.

[35] A. Omidkhoda, H. Mozdarani, A. Movasaghpoor and A.A.P. Fatholah, Study of apoptosis in labeled mesenchymal stem cells with superparamagnetic iron oxide using neutral comet assay, Toxicology in Vitro 21 (2007) 1191-1196.

[36] Y. Ozaki, M. Nishimura, K. Sekiya, F. Suehiro, M. Kanawa, H. Nikawa, T. Hamada and Y. Kato, Comprehensive analysis of chemotactic factors for bone marrow mesenchymal stem cells, Stem Cells Dev 16 (2007) 119-129.

[37] D.G. Phinney, M. Baddoo, M. Dutreil, D. Gaupp, W.T. Lai and I.A. Isakova, Murine mesenchymal stem cells transplanted to the central nervous system of neonatal versus adult mice exhibit distinct engraftment kinetics and express receptors that guide neuronal cell migration, Stem Cells Dev 15 (2006) 437-447.

[38] D. Portet, B. Denizot, E. Rump, J.J. Lejeune and P. Jallet, Nonpolymeric Coatings of Iron Oxide Colloids for Biological Use as Magnetic Resonance Imaging Contrast Agents, J Colloid Interface Sci 238 (2001) 37-42.

[39] J. Sanchez-Ramos, S. Song, F. Cardozo-Pelaez, C. Hazzi, T. Stedeford, A. Willing, T.B. Freeman, S. Saporta, W. Janssen, N. Patel, D.R. Cooper and P.R. Sanberg, Adult bone marrow stromal cells differentiate into neural cells in vitro, Exp Neurol 164 (2000) 247-256.

[40] E. Spaeth, A. Klopp, J. Dembinski, M. Andreeff and F. Marini, Inflammation and tumor microenvironments: defining the migratory itinerary of mesenchymal stem cells, Gene Ther 15 (2008) 730-738. 
[41] E. Sykova and P. Jendelova, In vivo tracking of stem cells in brain and spinal cord injury, Prog Brain Res 161 (2007) 367-383.

[42] E. Sykova and P. Jendelova, Magnetic resonance tracking of implanted adult and embryonic stem cells in injured brain and spinal cord, Ann N Y Acad Sci 1049 (2005) 146-160.

[43] E. Sykova and P. Jendelova, Migration, fate and in vivo imaging of adult stem cells in the CNS, Cell Death Differ 14 (2007) 1336-1342.

[44] V.M. Tatard, G. D'Ippolito, S. Diabira, A. Valeyev, J. Hackman, M. McCarthy, T.

Bouckenooghe, P. Menei, C.N. Montero-Menei and P.C. Schiller, Neurotrophin-directed differentiation of human adult marrow stromal cells to dopaminergic-like neurons, Bone 40 (2007) 360-373.

[45] T. Tondreau, L. Lagneaux, M. Dejeneffe, M. Massy, C. Mortier, A. Delforge and D. Bron, Bone marrow-derived mesenchymal stem cells already express specific neural proteins before any differentiation, Differentiation 72 (2004) 319-326.

[46] K.A. Trzaska, E.V. Kuzhikandathil and P. Rameshwar, Specification of a dopaminergic phenotype from adult human mesenchymal stem cells, Stem Cells 25 (2007) 2797-2808.

[47] L. Wang, Y. Li, X. Chen, J. Chen, S.C. Gautam, Y. Xu and M. Chopp, MCP-1, MIP-1, IL-8 and ischemic cerebral tissue enhance human bone marrow stromal cell migration in interface culture, Hematology 7 (2002) 113-117.

[48] G.P.a.C. Watson, The Rat Brain in Stereotaxic Coordinates, Second Edition, Academic Press, Inc (1986).

[49] D. Woodbury, E.J. Schwarz, D.J. Prockop and I.B. Black, Adult rat and human bone marrow stromal cells differentiate into neurons, J Neurosci Res 61 (2000) 364-370.

[50] S. Yano, S. Kuroda, H. Shichinohe, K. Hida and Y. Iwasaki, Do bone marrow stromal cells proliferate after transplantation into mice cerebral infarct?--a double labeling study, Brain Res 1065 (2005) 60-67. 
[51] J. Zhang, Y. Li, J. Chen, Y. Cui, M. Lu, S.B. Elias, J.B. Mitchell, L. Hammill, P. Vanguri and M. Chopp, Human bone marrow stromal cell treatment improves neurological functional recovery in EAE mice, Exp Neurol 195 (2005) 16-26.

[52] L.R. Zhao, W.M. Duan, M. Reyes, C.D. Keene, C.M. Verfaillie and W.C. Low, Human bone marrow stem cells exhibit neural phenotypes and ameliorate neurological deficits after grafting into the ischemic brain of rats, Exp Neurol 174 (2002) 11-20. 


\section{FIGURE LEGENDS}

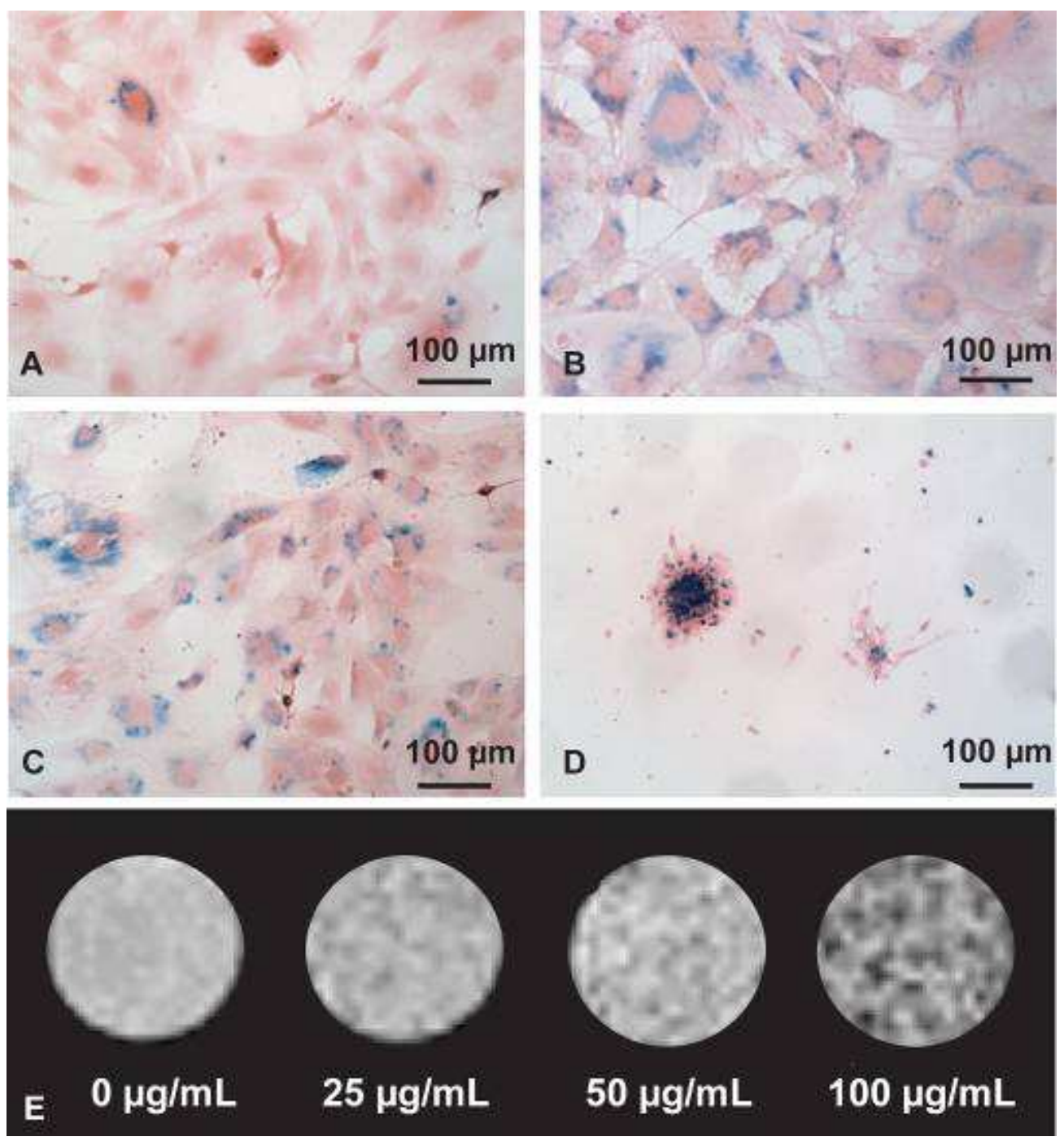

Fig. 1. In vitro Prussian blue assessment of iron uptake \& MRI. The intensity and the percentage of PB positive cells (in blue) increased with the iron concentration used. rMSC incubated for 48 hours with 25 , $50 \& 100 \mu \mathrm{g} / \mathrm{mL}$ iron (A, B \& C respectively). rNSC incubated for 24 hours with $50 \mu \mathrm{g} / \mathrm{mL}$ iron under adherent conditions (D). In vitro $\mathrm{T} 2 *$-weighted images $(\mathrm{TE}=15 \mathrm{~ms}$ ) of an agarose gel containing rMSC incubated for 48 hours in culture medium containing HEDP-coated nanoparticles (E). From left to right, iron concentration in the media was $0,25,50$ and $100 \mu \mathrm{g} / \mathrm{ml}$. 

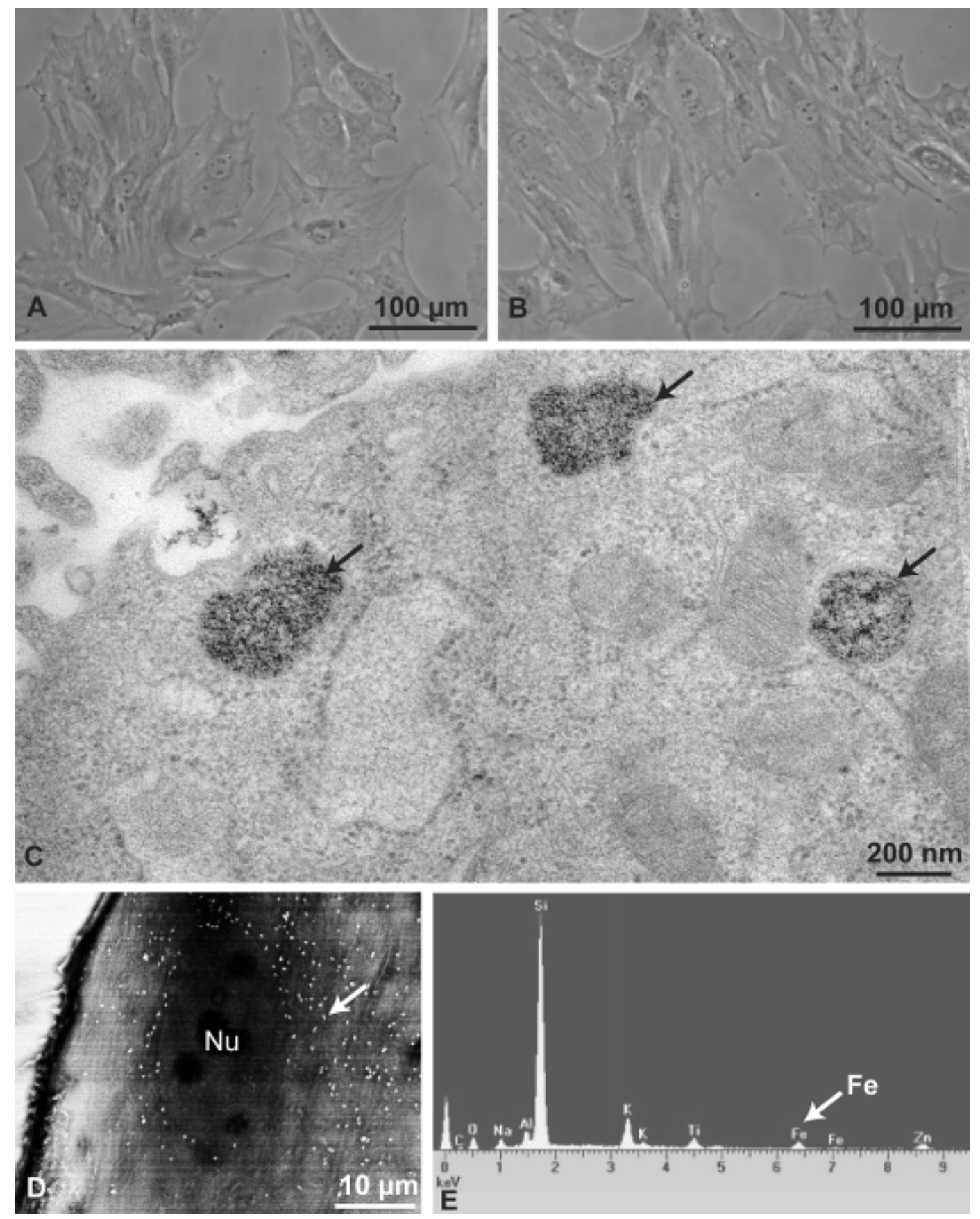

Fig. 2. Iron-labeled rMSC microscopical analysis. Morphology of unlabeled rMSC (A) was identical to rMSC labeled with $50 \mu \mathrm{g}$ iron/mL during 48 hours (B). TEM pictures showing the endo-lysosomial localization of the nanoparticles, iron in black (C). Back-scattered SEM picture $(11 \mathrm{kV})$, iron in white (D). EDX spectrum confirming the iron nature of the white dots observed by SEM (E). Nu: nucleus. 


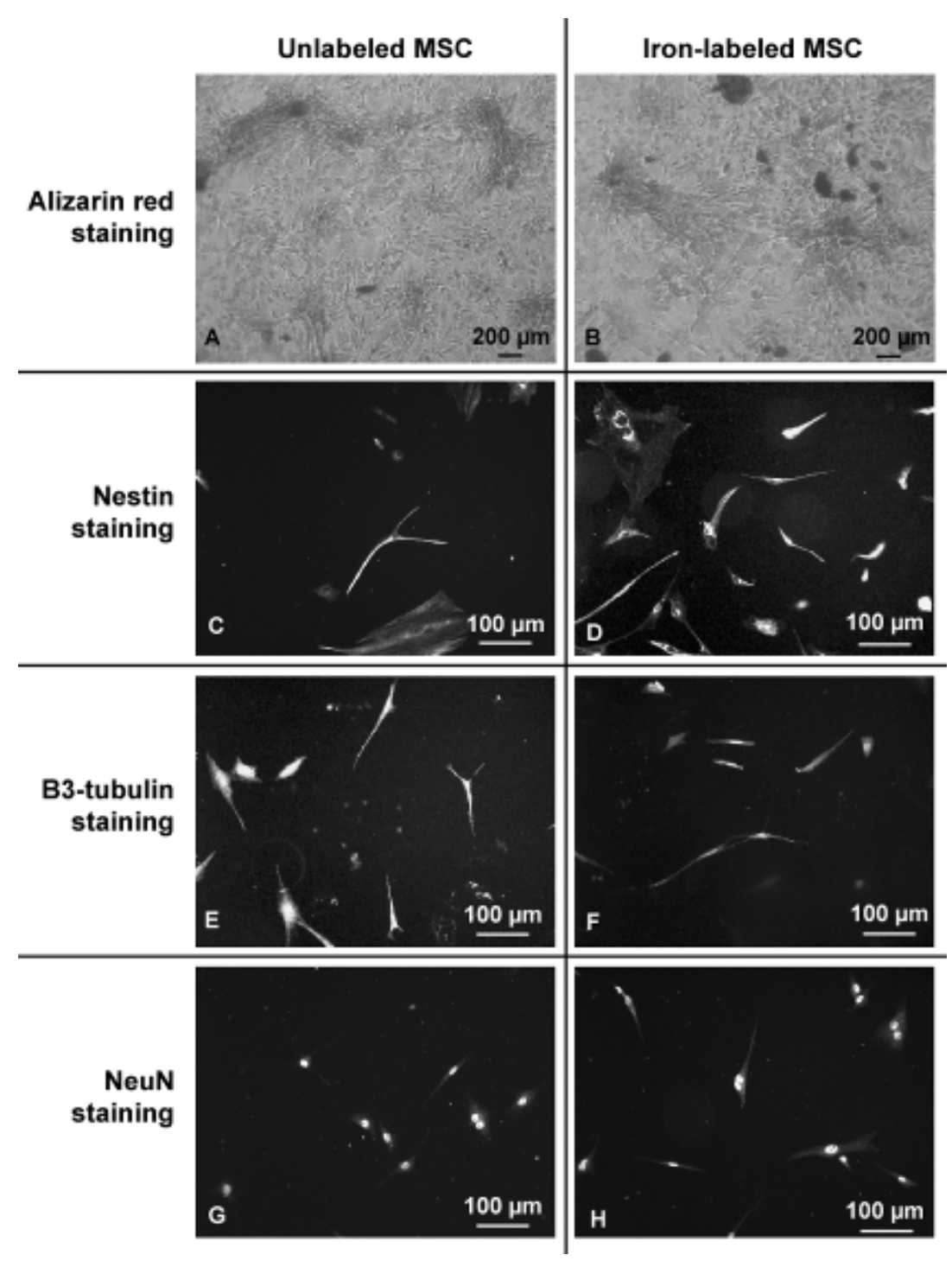

Fig. 3. rMSC in vitro differentiation. When induced toward the osteogenic lineage, unlabeled rMSC (A) as well as iron-labeled rMSC (B) produced hydroxyapatite calcium mineral deposits that stained red with Alizarin. After treatment with the neuronal induction media, flat rMSC acquired a narrower, spindle shaped morphology and exhibited an increased expression of the neural-related markers nestin and $\beta 3$-tubulin. The neuronal marker NeuN was already expressed in expanding cells and at every steps of the neuronal induction. Most importantly, unlabeled and iron-labeled rMSC responded similarly to the neuronal induction. Nestin, $\beta 3$-tubulin and NeuN expression 48 hours post-induction was identical for unlabeled (C, E \& G respectively) and iron-labeled $\mathrm{rMSC}$ (D, F \& H respectively). 


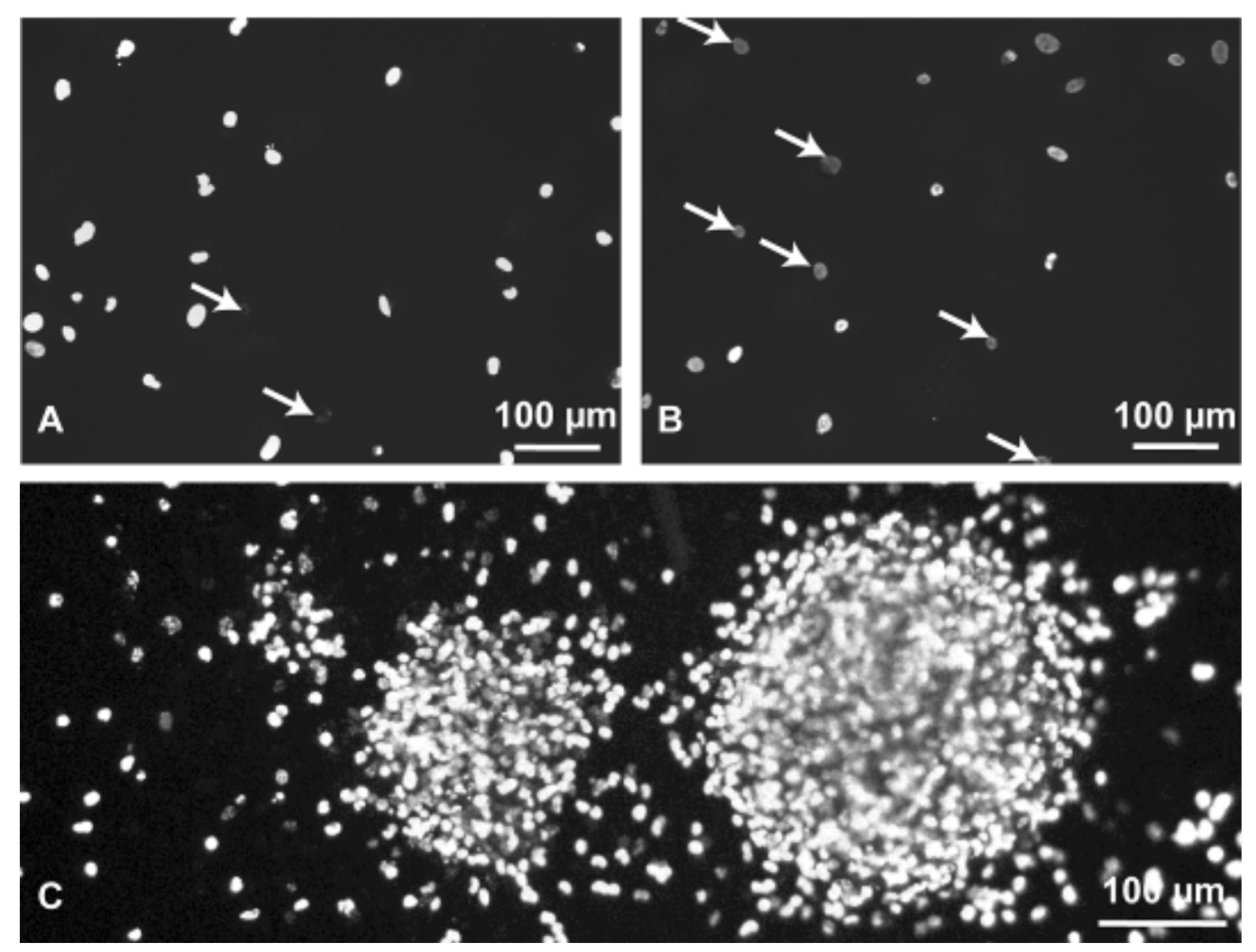

Fig. 4. BrdU immunofluorescent staining of iron-labeled rMSC and rNSC.

Ninety percent of rMSC were BrdU positive after 72 hours incubation (A) whereas only $40 \%$ were positive after 48 hours (B) (white arrowheads point out BrdU negative cells). Six hours incubation under adherent conditions was sufficient to label rNSC (C). 


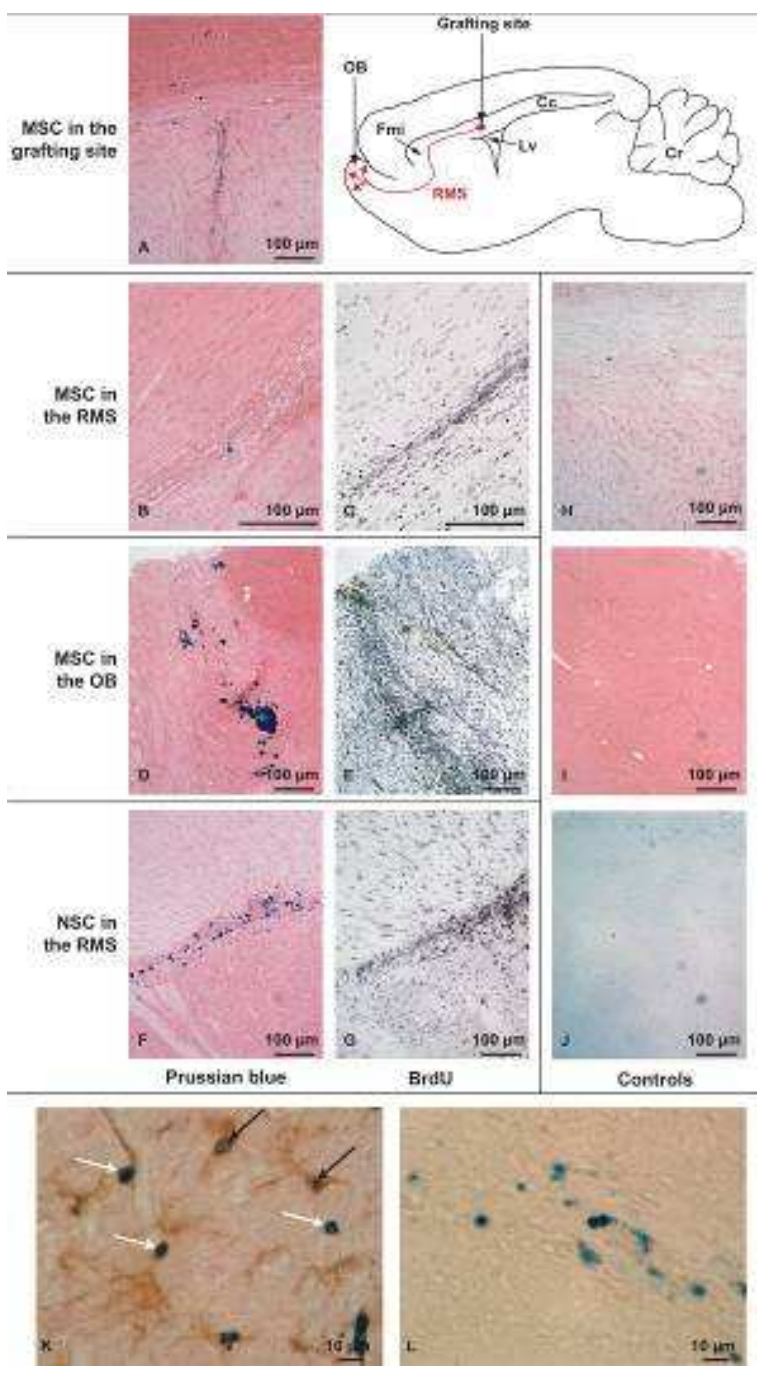

Fig. 5. rMSC migratory potential assessment by BrdU immunochemistry and PB staining 14 days after transplantation. Schematic cell migration is presented on top right corner. Grafted rMSC were detected in the grafting site (A), in the RMS (B, C) and in the OB (D, E) after grafting into the SVZ. rNSC migrated from the SVZ to the OB through the RMS (F, G). In sham-operated rats, injected with medium only, no PB staining was detected in the grafting site and in the $\mathrm{OB}$ (H \& I respectively). The BrdU isotypic control shows no background staining (J). In the grafting site, a fraction of Prussian blue positive cells co-localize with CD11b (K, black arrowheads), but not the entire rMSC population (K, white arrowheads). IgG2a isotype/Prussian blue staining shows no background (L). Cc: corpus callosum, Cr: cerebellum, Fmi: forceps minor corpus callosum, Lv: lateral ventricule. 


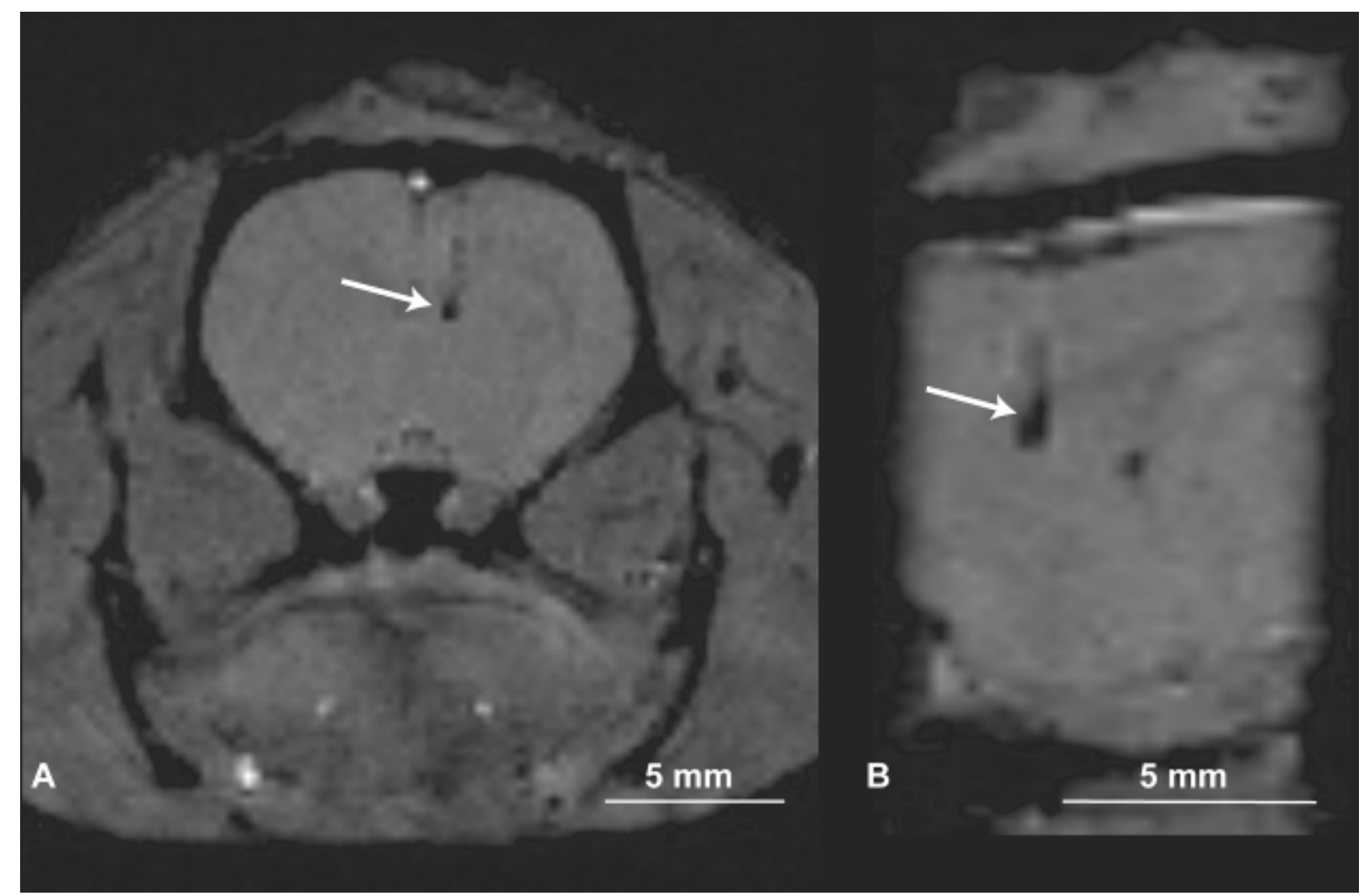

Fig. 6. MRI visualization of grafted cells. A focal deposit of rMSC was clearly detected at the grafting site 14 days after transplantation on axial (A) and sagittal (B) planes (white arrowheads). 